\title{
BELAJAR BERDASAR REGULASI DIRI DALAM PEMBELAJARAN DI PERGURUAN TINGGI
}

\author{
St. Nurjannah Yunus Tekeng \\ Fakultas Tarbiyah dan Keguruan UIN Alauddin \\ Jalan Sultan Alauddin Nomor 63 Makassar \\ Email: jannah.yustek@gmail.com
}

\begin{abstract}
Abstrak:
Belajar berdasar regulasi diri sangat penting bagi mahasiswa untuk dapat beradaptasi dengan tuntutan akademik dan sangat penting dalam proses pembelajaran seumur hidup untuk beradaptasi dengan tantangan hidup di masa depan. Belajar berdasar regulasi diri mengacu kepada peran aktif mereka dalam mengambil tanggung jawab dalam belajar atau kegiatan aktif dalam mengarahkan diri dalam belajar dengan meregulasi berbagai area seperti kognitif, perilaku, konteks, dan motivasi untuk mencapai tujuan pembelajarannya. Belajar berdasar regulsi diri didasarkan pada teori sosial kognitif dan faktor yang berngaruh dijelaskan dengan hubungan triadik resiprokal antara individu, perilaku, dan lingkungan. Selain itu, pengaruh positif belajar berdasar regulasi diri terhadap pembelajaran telah didukung oleh bukti empiris.
\end{abstract}

\begin{abstract}
Self-regulated learning is very important for university students to adapt with their academic demand and it is very critical in the lifelong learning process that allow them to face later real life challenges. It refers to their active role in taking responsibility with their learning or their active activities in directing themselves in learning and regulating many areas such as their cognitive, behavior, context, and motivation in order to achieve their learning goals. Self-Regulated learning is based on social cognitive theory and factor affecting it which is explained in the reciprocal triadic between individual, behavior, and environment. Besides, the positive influences of self-regulated learning on students learning have been supported by many empirical evidences.
\end{abstract}

\section{Kata kunci:}

Self-regulated learning, social cognitive theory, motivative and strategic learners

SALAH satu tuntutan belajar di perguruan tinggi adalah mahasiswa dapat menjadi pembelajar mandiri (independent learners). Belajar mandiri ini secara umum merujuk kepada jenis pembelajaran dimana mahasiswa mengambil tanggung jawab mengarahkan dan meregulasi proses belajar mereka sendiri. ${ }^{1}$ Kemandirian dalam belajar ini disebutnya juga sebagai belajar berdasar regulasi diri (Self-Regulated Learning) yang digambarkan sebagai kegiatan aktif mahasiswa mengarahkan dirinya dalam belajar atau mentransformasikan kemampuan mental ke dalam performa akademik atau keterampilan yang terkait dengan tugas-tugasnya. ${ }^{2}$

Fakta menunjukkan bahwa sebagian besar siswa yang mencapai studi yang lebih tinggi tidak cukup siap untuk menghadapi tuntutan atau tantangan di tingkat universitas karena mereka tidak mampu untuk meregulasi diri dalam proses belajar. ${ }^{3}$ 
Sebagai akibatnya banyak mahasiswa yang menunjukkan prestasi yang rendah dan drop out disebabkan oleh berbagai faktor, antara lain yaitu faktor internal mahasiswa, yaitu minat belajar yang rendah, kegagalan beradaptasi secara akademik dan sosial, serta kurangnya kemampuan mereka dalam mengarahkan diri atau belajar mandiri. ${ }^{4}$

Kemampuan untuk meregulasi diri sangat penting untuk pemelajar pada level manapun, khususnya pada tingkat perguruan tinggi, Ini disebabkan karena mahasiswa harus berkonfrontasi dengan banyaknya materi yang harus dikuasai dan banyaknya tugas yang harus dikerjakan dalam waktu yang terbatas. ${ }^{5}$ Lebih detail digambarkan kecemasan tertinggi yang mungkin dihadapi oleh mahasiswa disebabkan oleh besarnya tantangan yang harus mereka hadapi seperti banyaknya informasi yang mereka harus kuasai dan banyaknya makalah yang harus mereka tulis, melakukan presentasi, mempersiapkan diri dalam ujian dan di samping itu mereka juga dituntut harus tetap memelihara hubungan sosial yang baik. ${ }^{6}$

Dalam perspektif yang lebih luas, mahasiswa yang sukses biasanya digambarkan sebagai mahasiswa yang meregulasi diri dalam belajar. Hal ini dikarenakan mahasiswa mengarahkan belajarnya dengan menggunakan sejumlah strategi kognitif, metakognitif, motivasional, dan supportif yang memungkinkan mereka untuk mengkonstruksi pengetahuan, dapat meregulasi dan mengontrol keseluruhan proses belajar secara intensional, yaitu mengetahui keterampilan dan pengetahuan yang mereka miliki, memahami apa yang harus mereka lakukan untuk belajar, memonitor perilaku belajarnya, mencocokkan perilaku dan aktivitas dengan tuntutan studi, dan mampu meregulasi motivasi. ${ }^{7}$

Mahasiswa harus dimotivasi agar memiliki komitmen terhadap tujuan pendidikan yang bermakna, berusaha untuk mendapatkan keuntungan dari pengalaman pendidikan mereka, memonitor kemajuan menuju pencapaian tujuan, membuat penyesuaian dalam upayanya ketika diperlukan, dan menetapkan tujuan yang baru dan lebih menuntut karena ketercapaian tujuan sebelumnya. ${ }^{8}$ Secara umum, belajar berdasar regulasi diri memungkinkan mahasiswa untuk mandiri sambil belajar bermakna dan konstruktif sepanjang kehidupan mereka. ${ }^{9}$

Belajar berdasar regulasi diri (Self-Regulated Learning) sangat penting bagi mahasiswa, khususnya dalam konteks pembelajaran yang menekankan pada pendekatan berpusat pada mahasiswa (student centered approach). Pendekatan belajar ini menuntut keterlibatan aktif mahasiswa dalam pembelajaran, atau bentuk pembelajaran yang menuntut adanya kebutuhan untuk beralih dari kegiatan dosen mengajar menjadi lebih kepada praktek refleksi diri bagi mahasiswa. ${ }^{10}$

Sukses dalam belajar berdasar regulasi diri sangat esensi dan sebagai fungsi adaptif dalam semua aspek kehidupan manusia.11 Selain itu, belajar berdasar regulasi diri penting karena fungsi utama pendidikan adalah mengembangankan keterampilan belajar seumur hidup. ${ }^{12}$ Pendapat yang sama menyatakan bahwa regulasi diri dalam belajar dianggap sebagai salah satu keterampilan yang sangat penting dan dibutuhkan untuk proses belajar sepanjang masa, dan sesuai dengan tujuan utama pendidikan tinggi yaitu menghasilkan pembelajar seumur hidup (lifelong learners). ${ }^{13}$ 
Berkembangnya kemampuan mahasiswa dalam mengarahkan dirinya atau kemampuan untuk meregulasi diri dalam belajar dapat menentukan daya saing mereka di era globalisasi di masa depan dan menjadi prediktor kesuksesan individu dalam mencapai tujuan. Hal ini dikarenakan mahasiswa yang meregulasi diri dalam belajar dikarakteristikkan sebagai pembelajar strategik, mampu mengontrol dan bertanggung jawab terhadap pembelajarannya, ${ }^{14}$ memiliki motivasi yang superior, metode belajar yang adaptif, sukses secara akademik, dan memandang masa depannya secara optimis. ${ }^{15}$

Berdasarkan uraian di atas, untuk dapat memahami konsep belajar berdasar regulasi diri diperguruan tinggi dan peranan pentingnya bagi mahasiswa, maka artikel ini bertujuan untuk memberikan gambaran tentang proses belajar berdasar regulasi diri dan efek positif yang ditimbulkannya berdasarkan bukti empiris dari hasil penelitian.

\section{PEMBAHASAN}

\section{Pengertian Belajar Berdasar Regulasi Diri}

Belajar berdasar regulasi diri (BBRD) adalah usaha motivatif dan strategik siswa untuk mencapai tujuan khusus. BBRD ini bersifat fungsional, personal, dan independen atau lebih spesifik lagi yaitu pencarian ilmu pengetahuan dan pemecahan masalah yang strategik yang dinilai sebagai proses berpikir kritis atau pemikiran yang sungguh-sungguh. ${ }^{16}$ BBRD adalah bentuk belajar yang spesifik yang teregulasi secara internal dan kriteria terpenting dari BBRD ini adalah mahasiswa memiliki kontrol terhadap belajar mereka sendiri, mengarahkan proses kognitif dan motivasi untuk mencapai tujuan pembelajaran. Sehingga otomatis BBRD ini diasumsikan bersifat intensional dan implikasinya adalah dilakukan secara sadar. ${ }^{17}$

Belajar berdasar regulasi diri mengacu kepada menghasilkan pemikiran sendiri, perasaan, dan tindakan yang terencana dan dengan secara siklus diadaptasikan dengan pencapaian tujuan personal.18 Belajar berdasar regulasi diri adalah suatu proses yang aktif dan konstruktif dimana individu menetapkan tujuan belajar dan kemudian berusaha untuk memantau, mengatur, dan mengontrol kognisi, motivasi, dan perilaku, dibimbing dan dibatasi oleh tujuan, dan fitur kontekstual dalam lingkungan. ${ }^{19}$

Belajar berdasar regulasi diri didefinisikan sebagai suatu proses yang diarahkan pada tujuan di mana mahasiswa terlibat dalam refleksi diri dan evaluasi diri untuk memperoleh hasil belajar yang diinginkan.20 Dalam belajar berdasar regulasi diri, individu menetapkan standar pembelajaran tertentu, sengaja memilih strategi untuk mencapai tujuan tersebut (misalnya perencanaan), terlibat dalam berbagai keterampilan (misalnya pengujian diri) untuk memantau perkembangan mereka, dan membuat modifikasi (misalnya merevisi standar) ketika dihadapkan dengan rintangan. ${ }^{21}$ Kedua definisi ini bermakna bahwa pemikiran, perasaan, dan tindakan yang direncanakan oleh mahasiswa diorientasikan dalam pencapaian tujuan pembelajaran mereka. 
Implikasi dari teori ini, agar kemampuan regulasi diri pada individu berkembang, maka mereka harus diizinkan untuk bekerja menurut konteksnya dimana berdasarkan tujuan pembelajarannya, mereka menciptakan episode belajarnya (learning episode), yaitu suatu situasi dimana seseorang diundang, dibimbing, atau diyakinkan untuk menunjukkan tingkah laku konteks spesifik dan menentukan tujuan belajar yang terarah. 22

Belajar berdasar regulasi diri mengacu kepada proses mengarahkan diri dan keyakinan diri yang memungkinkan individu mentransformasi kemampuan berpikir mereka, seperti bakat verbal, menjadi keterampilan performa akademik, seperti menulis. ${ }^{23}$ Belajar berdasar regulasi diri dipandang sebagai proses proaktif yang digunakan pemelajar untuk memperoleh keterampilan akademis, seperti menetapkan tujuan, memilih dan mengembangkan strategi, dan memonitor efektivitas diri.

Meskipun Belajar berdasar regulasi diri dipandang sangat penting khususnya dalam bentuk pengarahan diri dalam belajar, seperti belajar penemuan, atau mencari informasi sendiri dari berbagai sumber, namun juga dianggap penting dalam bentuk belajar sosial seperti mencari bantuan dari teman, orang tua, dan guru. Isu utamanya adalah apakah pemelajar menampilkan inisiatif pribadi, ketekunan, dan keterampilan adaptif. Kualitas proaktif ini berasal dari perasaan dan keyakinan motivasi yang menguntungkan, serta strategi metakognitif.

Reformasi baru dalam dunia pendidikan adalah dimana tujuan pembelajaran tidak hanya berpusat pada kegiatan mentransfer pengetahuan tetapi juga memberi kesempatan untuk mengkonstruksi pengetahuan melalui belajar berdasar regulasi diri atau pengaplikasian berpikir tingkat tinggi. ${ }^{24}$ Oleh karena itu, BBRD didefinisikan sebagai "students can be described as self- regulated to the degree that they are metacognitively, motivationally, and behaviorally active participants in their own learning process. ${ }^{25}$ Ini bermakna bahwa kemampuan belajar berdasar regulasi diri mahasiswa dapat terlihat pada partisipasi aktifnya yang bersifat metakognitif, termotivasi dan tergambar pada tingkah laku dalam proses belajarnya. Dalam proses metakognitif, pembelajar dengan regulasi diri menentukan tujuan, membuat perencanaan, melakukan monitor diri, dan mengevaluasi berbagai hal dalam proses pemerolehan informasi. Proses ini memungkinkan mereka memiliki kesadaran diri, berpengetahuan, dan menentukan pendekatan belajarnya. Dalam proses motivasi, pemelajar dengan regulasi diri menunjukkan efikasi diri yang tinggi, atribusi diri, dan minat intrik terhadap tugas. Mereka adalah inisiator yang menunjukkan usaha yang luar biasa dan persisten dalam belajar. Dalam proses behavioral, mereka memilih, dan mengatur, dan menciptakan lingkungan yang mengoptimalkan belajar. Misalnya, mereka meminta saran, informasi, dan mencari tempat dimana mereka lebih dapat belajar.

Belajar berdasar regulasi diri melibatkan lebih dari sekedar kemampuan untuk melakukan sebuah respon belajar oleh diri sendiri (kontrol diri) dan lebih dari kemampuan untuk menyesuaikan respon belajar terhadap kondisi baru dan berubah yang berasal dari umpan balik negatif, tetapi juga melibatkan usaha proaktif untuk 
mencari keuntungan dari kegiatan belajar. pada level ini, individu tidak hanya mengarahkan diri dalam metakognitif tetapi juga motivasi diri. ${ }^{26}$ Keterampilan dan keinginan mereka terintegrasi kedalam komponen belajar berdasar regulasi diri. Esensi dari belajar berdasar regulasi diri adalah integrasi antara kognisi, motivasi dan afeksi atau dengan kata lain, penyatuan antara keterampilan dan keinginan. ${ }^{27}$

Belajar berdasar regulasi diri adalah kontrol yang dimiliki oleh mahasiswa terhadap: (1) kognisi, yang merupakan komponen kognitif dari regulasi diri yang dikenal dengan metakognisi; (2) perilaku, yaitu kontrol terhadap apa yang dilakukan oleh siswa untuk mencapai tujuan; (3) emosi, yaitu kontrol yang sangat dibutuhkan karena adanya pengalaman emosi ketika mahasiswa mengerjakan tugas akademik yang mungkin dapat menghambat kinerja/performa mereka; (4) motivasi, yaitu kontrol yang terdiri atas kesadaran mahasiswa terhadap motivasinya, menimbulkan motivasi diri, memelihara minat dan perhatian selama mengerjakan tugas. Kontrol terhadap motivasi penting karena motivasi mempengaruhi ketertarikan terhadap tugas. 28

\section{Dasar Teori Belajar Berdasar Regulasi Diri}

Belajar berdasar regulasi diri didasarkan pada teori belajar sosial kognitif. Manusia dipandang memiliki kemampuan untuk mengarahkan diri sehingga memungkinkan mereka melakukan kontrol terhadap pikiran, perasaan dan tindakan dalam mencapai tujuan yang diharapkan. Mereka menetapkan standar internal bagi dirinya yang kemudian berfungsi sebagai landasan evaluasi diri dan insentif diri atau sebagai motivator. ${ }^{29}$ Ada tiga komponen proses dari regulasi diri yaitu: (1) proses pengamatan diri yang berfungsi memberikan informasi dalam menetapkan standar yang realistis dan untuk mengevaluasi perilaku; (2) proses penilaian diri, yaitu menilai positif dan negatifnya perilaku sebagai bahan evaluasi perubahan yang terjadi dalam perilaku atau evaluasi kemajuan diri. dalam proses ini individu melakukan perbandingan terhadap norma-norma standar, kinerja orang lain, dan kinerja diri sendiri di masa lalu. Individu akan cenderung kepada sesuatu yang dianggap bernilai bagi mereka; dan (3) proses reaksi diri. Operasi dari ketiga komponen ini bergantung kepada adanya target tujuan..$^{30}$

Regulasi diri adalah karakteristik manusia yang khusus dan adaptif, yang memungkinkan mereka mengubah respon termasuk mengubah diri untuk memenuhi standar sosial atau standar lainnya. Teori sosial kognitif berasumsi bahwa manusia tidak hanya diarahkan oleh lingkungan eksternal, akan tetapi mereka juga memiliki kemampuan untuk mengorganisasi, menjadi proaktif, merefleksi, and meregulasi diri mereka. Manusia memiliki kekuatan untuk mempengaruhi tindakan mereka untuk mencapai tujuan atau kapasitas untuk mengontrol proses berpikir dan motivasi yang beroperasi melalui mekanisme agen personal. ${ }^{31}$

Faktor-faktor yang berpengaruh terhadap belajar berdasar regulasi diri dapat dipahami melalui perspektif teori sosial kognitif. Menurut teori ini, belajar berdasar regulasi diri adalah sebuah model belajar yang didasari oleh asumsi triadik resiprokalitas. Asumsi ini menyatakan bahwa pengelolaan diri dalam belajar 
dipengaruhi oleh interaksi antara tiga faktor determinan yaitu individu, perilaku, dan lingkungan. Setiap faktor menjadi kausalitas bagi faktor yang lain, oleh karena itu disebut triadic reciprocality. 32

\section{Model Belajar Berdasar Regulasi Diri di Perguruan Tinggi}

Model belajar berdasar regulasi diri yang dikembangkan oleh Pintrich menggambarkan kerangka konseptual tentang bagaimana belajar berdasar regulasi diri bagi mahasiswa. Model belajar berdasar regulasi diri ini didasarkan pada empat asumsi umum yaitu bahwa individu dalam belajar berdasar regulasi diri, (1) dipandang sebagai partisipan aktif dalam pembelajaran; (2), memiliki potensi untuk memonitor, mengontrol, dan meregulasi banyak aspek, yaitu kognisi, mempengaruhi, perilaku, dan konteks; (3), menentukan berbagai macam tujuan atau standar sebagai pembanding untuk menentukan apakah mereka harus melanjutkan atau melakukan beberapa perubahan dalam pembelajaran mereka; dan (4) bahwa kegiatan belajar berdasar regulasi diri adalah mediator antara karakteristik individu dan kontekstual. 33

Model belajar berdasar regulasi diri Pintrich ini terdiri atas empat tahapan. ${ }^{34}$ Fase pertama adalah goal setting. Termasuk dalam fase ini adalah penetapan tujuan, aktivasi pengetahuan awal tentang isi materi, dan pengetahuan metakognitif (domain kognitif); adaptasi orientasi tujuan, dan penilaian efikasi (motivasi/domain afektif); usaha merencanakan (domain perilaku), dan persepsi terhadap tugas dan isi (domain isi). Fase kedua adalah monitoring, yaitu kegiatan mahasiswa untuk melakukan perubahan adaptif (jika dibutuhkan) dan secara bersamaan membuat kemajuan terhadap sebuah tujuan khusus. Seperti halnya pada fase pertama, termasuk dalam fase ini juga adalah kesadaran metakognitif dan monitoring kognisi, afeksi, motivasi, usaha, dan penggunaan waktu. Fase ketiga adalah control, yaitu seleksi dan adaptasi strategi kognitif untuk belajar, berpikir, motivasi dan afeksi. Fase keempat adalah reflection. Termasuk dalam fase ini adalah penilaian kognitif, reaksi afektif, pemilihan perilaku, dan evaluasi tugas.

Keempat fase ini merepresentasikan secara umum sekuensi susunan waktu yang akan dilalui individu ketika mereka mengerjakan sebuah tugas. Akan tetapi tidak ada asumsi yang kuat bahwa fase-fase ini terstruktur secara hirarki atau linier, dimana fase awal terjadi dahulu sebelum fase berikutnya. Hal ini dikarenakan dalam berbagai model belajar berdasar regulasi diri, pemantauan, kontrol dan reaksi dapat terjadi secara simultan dan secara dinamis ketika individu mengalami kemajuan selama mengerjakan tugas, dimana tujuan dan rencana dirubah atau diperbarui berdasarkan umpan balik dari proses pemantauan, kontrol, dan reaksi. ${ }^{35}$

Model belajar berdasar regulasi diri mahasiswa Pintrich ini terdiri atas empat area regulasi yaitu regulasi kognisi, perilaku, motivasi/afek, perilaku, dan konteks. ${ }^{36}$

\section{Regulasi Kognisi (Cognition Regulation)}

Regulasi kognisi adalah keterlibatan mahasiswa dalam kegiatan, strategi dan taktik merencanakan, memonitor, dan meregulasi kognisi. Termasuk dalam kegiatan 
merencanakan dan forethought adalah membuat target khusus atau tujuan kognitif belajar, pengaktifan pengetahuan awal (prior knowledge) tentang materi yang akan dipelajari, dan pengaktifan pengetahuan metakognitif yang dimiliki mahasiswa terhadap tugas dan dirinya. Selain itu, aspek terpenting dari regulasi kognisi adalah monitoring kognisi. Mahasiswa harus menyadari dan memantau perkembangannya dalam mencapai tujuannya, dan memantau pembelajaran dan pemahaman mereka agar mereka dapat membuat perubahan adaptif dalam belajarnya.

Regulasi kognisi dalam model ini mencakup jenis-jenis kegiatan kognitif dan metakognitif dimana mahasiswa terlibat untuk beradaptasi dan merubah kognisinya. Dalam model ini diasumsikan bahwa usaha-usaha untuk mengontrol, meregulasi, dan merubah kognisi harus terkait dengan monitoring kegiatan-kegiatan kognisi yang memberikan informasi tentang diskrepansi relatif antara sebuah tujuan dan kemajuan sekarang untuk mencapai tujuan tersebut. Sebagai contoh, jika seorang mahasiswa membaca sebuah buku teks dengan tujuan untuk memahami (dan bukan hanya menyelesaikan tugas membaca), maka pada saat mahasiswa tersebut memonitor pemahamannya, proses monitoring ini memberikan informasi tentang kebutuhan untuk merubah strategi membacanya. Reaksi dan refleksi mahasiswa terhadap penilaian kognitifnya tentang bagaimana mereka melakukannya dan atribusinya terhadap performanya dapat menjadi bagian dari usahanya untuk meregulasi belajarnya.

Aspek sentral dari kontrol dan regulasi kognisi ini adalah seleksi nyata dan penggunaan berbagai strategi kognitif dan strategi belajar berdasar regulasi diri. Terdapat berbagai macam strategi kognitif terkait memori, belajar, reasoning, pemecahan masalah, dan berpikir. Dalam penelitian belajar berdasar regulasi diri terdapat sejumlah strategi kognisi dan belajar yang dapat digunakan individu untuk membantu mereka memahami materi kuliah, antara lain pengulangan (rehearsal), elaborasi, organisasi, berpikir kritis, dan strategi metakognisi yang digunakan untuk mengontrol kognisi.

\section{Regulasi Motivasi/Afek (Motivation/Affect Regulation)}

Area regulasi ini mencakup usaha untuk meregulasi berbagai keyakinan motivasi seperti tujuan menyelesaikan tugas, efikasi diri, persepsi tentang kesulitan tugas, keyakinan nilai tugas, dan minat personal terhadap tugas. Selain keyakinan motivasi ini, mahasiswa juga dapat berusaha mengontrol afek dan motivasi mereka melalui berbagai strategi yang disebut coping strategies, yaitu strategi yang dapat membantu mereka beradaptasi dengan afek negatif seperti ketakutan dan kecemasan.

\section{Regulasi Perilaku (Behavior Regulation)}

Regulasi perilaku adalah usaha individu mengontrol perilakunya. Berdasarkan model-model intensi (model of intension), intensi terencana, dan perilaku yang direncanakan menunjukkan pembentukan intensi yang terkait dengan sejumlah perilaku dalam berbagai domain yang berbeda. Misalnya, dalam domain pembelajaran akademik, perencanaan waktu dan usaha merupakan kegiatan yang menjadi bagian 
dari kontrol perilaku. Kontrol usaha adalah melibatkan tindakan untuk mengontrol usaha agar dapat menghasilkan pembelajaran yang baik pada mata kuliah, atau dimaknai sebagai pengaturan usaha yang merefleksikan komitmen untuk mencapai tujuan meskipun mendapatkan kesulitan dan gangguan atau tugas yang tidak menarik. ${ }^{37}$ Adapun pengaturan waktu mencakup pembuatan jadwal belajar dan alokasi waktu terhadap kegiatan yang berbeda-beda. Selain itu, pengaturan waktu juga mencakup pembuatan keputusan dan pembentukan intensi tentang bagaimana mahasiswa mengalokasikan usahanya dan intensitas pekerjaannya.

Selain regulasi usaha dan pengaturan waktu, strategi regulasi perilaku juga terkait dengan mencari bantuan (help seeking). Mahasiswa yang meregulasi diri, mengetahui kapan, mengapa, dan dari mana mereka dapat mencari bantuan. ${ }^{38}$ Mencari bantuan merupakan strategi prilaku karena melibatkan perilaku individu, akan tetapi juga melibatkan kontrol ontekstual yang penting untuk mendapatkan bantuan dari orang lain di lingkungan. Sebagai kesimpulan, perilaku mencari bantuan sebagai sebuah interaksi sosial, merefleksikan pentingnya mempertimbangkan konteks sosial belajar (the social nature of learning)

\section{Regulasi Konteks (Context Regulation)}

Regulasi konteks adalah proses regulasi yang melibatkan usaha untuk mengontrol dan meregulasi tugas dan konteks yang dikonfrontasikan kepada mahasiswa. Dibandingkan dengan aspek regulasi lainnya, aspek regulasi ini kemungkinan lebih sulit. Hal ini disebabkan karena area regulasi ini tidak berada pada kontrol langsung dari pebelajar, akan tetapi lingkungan memiliki peranan dalam keberhasilan mereka melakukan regulasi pada aspek ini.

Model kontrol volitional biasanya mencakup sebuah istilah yang diberi nama kontrol lingkungan yang mengacu kepada usaha-usaha untuk mengontrol dan mengatur lingkungan dengan cara yang dapat menfasilitasi pencapaian tujuan dan penyelesaian tugas. Dalam belajar berdasar regulasi diri, kebanyakan model memasukkan strategi membentuk dan mengontrol kondisi lingkungan belajar sebagai strategi penting dalam belajar berdasar regulasi diri.

Dalam konteks kelas traditional, semua aspek tugas dan konteks dikontrol oleh instruktur/pengajar, sehingga memberikan sedikit peluang yang diberikan kepada pembelajar untuk terlibat dalam kontrol dan regulasi konteks. Akan tetapi, dalam konteks pembelajaran saat ini yang menggunakan pendekatan students centered, pembelajar diminta untuk lebih banyak melakukan kontrol dan regulasi nyata terhadap tugas-tugas akademik dan suasana, dan struktur kelas. Mereka seringkali diminta untuk mendesain sendiri projek mereka, bekerja kelompok secara kolaboratif dan kooperatif, mendesain cara mengumpulan data, atau bahkan bekerja sama dengan pengajar untuk menentukan bagaimana mereka dievaluasi pada tugastugasnya.

Jenis pembelajaran seperti ini tentu saja menawarkan banyak otonomi dan tanggung jawab pembelajar, dan menciptakan berbagai macam kesempatan untuk kontrol dan regulasi konteks. Pada tingkat universitas, kesempatan mahasiswa untuk 
dapat mengontrol dan meregulasi konteks sangatlah besar. Bahkan mereka dituntut untuk dapat mengontrol dan meregulasi lingkungan. Sebagai contoh, memonitor lingkungan belajar untuk menghindari gangguan, membuat lingkungan belajar lebih kondusif seperti mengorganisasi tempat belajar khusus, dan kemampuan untuk bekerja sama dengan teman dalam kelompok belajar atau belajar kelompok kooperatif yang penting yang mempersyaratkan interaksi dengan teman dalam kelompok (peer interaction) dan belajar kelompok (peer learning).

\section{Dukungan Empiris terhadap Belajar Berdasar Regulasi Diri}

Berbagai hasil penelitian telah memberikan bukti empiris yang menunjukkan pentingnya peranan belajar berdasar regulasi diri diantaranya adalah menunjukkan pengaruh yang signifikan terhadap prestasi akademik, ${ }^{39}$ penundaan kepuasan akademik atau intensi untuk menunda mendapatkan reward jangka pendek degan reward jangka panjang yang lebih baik yang kemudian berefek pada pengalaman belajar dan kesuskesan akademik, ${ }^{40}$ penurunan pada gaya atribusi pesimis, dan meningkatkan dimensi atribusi internal, ${ }^{41}$ peningkatan penggunaan pendekatan belajar mendalam (deep learning) dan penurunan penggunaan pendekatan belajar surface learning, ${ }^{42}$ menurunkan prokrastinasi akademik penulisan skripsi pada mahasiswa, ${ }^{43}$ dan berkorelasi positif dengan motivasi berprestasi. ${ }^{44}$

\section{SIMPULAN}

Berdasarkan uraian di atas, dapat diambil kesimpulan bahwa belajar berdasar regulasi sangat penting bagi mahasiswa untuk sukses dalam pembelajaran dan dapat menunjang keterampilan mereka sebagai pemelajar sepanjang masa sesuai dengan tujuan utama pendidikan tinggi. Selain itu, belajar berdasar regulasi diri sesuai dengan karakteristk manusia, yaitu memiliki potensi sehingga mereka dapat mengarahkan dirinya berdasarkan penjelasan dari teori sosial kognitif. Selain itu, pengaruh positif yang ditimbulkannya telah dibuktikan secara empiris oleh beberapa hasil penelitian

\section{CATATAN AKHIR}

1. R. Balapumi \& A. Aitken, "Concepts and Factors Influencing Independent Learning in IS Higher Education", 23rd Australasian Conference on Information Systems, 2012.

2. B. J. Zimmerman "Investigating self-regulation and motivation: Historical background, methodological developments, and future prospects", American Educational Research Journal, (Vol. 45, No. 1, 2008), h. $166-183 .$.

3. A. Valle, J. C. Núñez, R. G. Cabanach, J. A. González-Pienda, S. Rodríguez, P. Rosário, ... M. A. Muñoz-Cadavid, Self-regulated profiles and academic achievement, Psicothema. (Vol. 20, no 4, 2008), h. 724-731.

4. Khusnul Ashar, Tahun 2012 Jumlah Mahasiswa S1 FEB UB yang Drop Out Sebanyak 70 Orang, Diakses dari http://feb.ub.ac.id/tahun-2012-jumlah-mahasiswa-s1-feb-ub-yangdi-drop-sebanyak-70-orang.html\#.VBYpi6MZh Ow pada tanggal 12 September 2014. 
5. M. T. Cohen, "The importance of self-regulation for college student learning", College Student Journal, (Vol. 46, No. 4, 2012).

6. M. T. Cohen, The Importance of Self-regulation for College Student Learning, (2012)

7. J. C. Núñez, R. Cerezo, A. Bernardo, P. Rosário, A. Valle, E. Fernández, E., \& N. Suárez, "Implementation of Training Programs in Self-regulated Learning Strategies in Moodle Format: Results of a Experience in Higher Education, (2011), h. 274-281.

8. Miller, R. B., \& Brickman, S. J., A Model of Future-Oriented Motivation and SelfRegulation, Educational Psychology Review, (Vol. 16, No. 1, 2004)

9. J. C. Núñez, R. Cerezo, A. Bernardo, P. Rosário, A. Valle, E. Fernández, E., \& N. Suárez, "Implementation of Training Programs in Self-Regulated Learning Strategies in Moodle Format: Results of a experience in higher education, (2011), h. 274-281.

10. D.H. Schunk \& B. J. Zimmerman, Self-Regulated Learning: From Teaching to Reflective Practice, dikutip oleh F. T. Montalvo, \& Maria C.G.Tores, Self-regulated learning: Current and future direction. (Spain: Department of Education, Univerdad de Navarra, 2004).

11. Hoyle. Rick H, "Personality and self-Regulation: Trait and Information-Processing Perspectives". Journal of Personality, (2006), 74:6.

12. B. J. Zimmerman, "Becoming a Self-Regulated Learner: An Overview". Theory Into Practicve, (Vol. 41, No. 2, 2002), h. 64-70.

13. D. Ifenthaler, "Determining the Effectiveness of Prompts for Self-Regulated Learning in Problem-Solving Scenarios", Educational Technology \& Society, 15 (1), (2012), h. 38-52.

14. M. Arabzadeh, P. Kadivar, \& A. Dlavar, "The Effects of Teaching Self-Regulated Learning Strategy on Students' Academic Delay of Gratification", Interdisiplinary Journal of Contemporary Research Business, (Vol. 4, No. 2., 2012),

15. B. J. Zimmerman, “Becoming a Self-Regulated Learner: An Overview”, , h. 64-70.

16. S. G. Paris \& L. R. Ayres, Becoming Reflective Students and Teachers: With Portfolios and Authentic Assessment, (Washington DC: American Psychological Association, 1994), h.

17. Boekaerts, M., \& Cascallar, E., "How Far Have we Moved Toward the Integration of Theory and Practice in Self-Regulation", Educational Psychological Review, (2006), 18:199-210.

18. Zimmerman, B. J., Attaining self-regulated: "A Social Cognitive Perspective", dalam M. Boekaerts, P. R. Pintrich, dan M Zeidner, Handbook of Self-Regulation, (Sandiego: Academic Press, 2000), h. 13-39.

19. Pintrich, P. R., "The Role of Goal Orientation in Self-Regulated Learning", dalam M. Boekaerts, P. R. Pintrich, \& M. Zeidner, Eds, Handbook of self-regulation, (San Diego, CA: Academic, 2000), h. 451-502..

20. R. B. Miller \& S. J.Brickman, A Model of Future-Oriented Motivation and Self-Regulation, (2004).

21. P.H. Winne, "A Perspective on State-of-the-art Research on Self-Regulated Learning", Instructional Science, (2005), 33: 559-565.

22. M. Boekaerts \& M. Niemivirta, "Self-Regulated Learning: Finding a Balance Between Learning Goals and Ego-Protective Goals", dalam M. Boekaerts, P. R. Pintrich, dan M Zeidner, Handbook of Self-Regulation, (Sandiego: Academic Press, 2000), h. 417- 450.

23. B. J. Zimmerman, "Investigating Self-Regulation and Motivation: Historical Background, Methodological Developments, and Future Prospects", American Educational Research Journal, (Vol. 45, No. 1, 2008), h. 166-183. 
24. B. Kramarski \& T. Michalsky, "Investigating Preservice Teachers' Professional Growth in Self-Regulated Learning Environments", Journal of Educational Psychology, (Vol 101(1), 2009), h. 161-175.

25. B. J. Zimmerman, "Self-Regulated Learning and Academic Achievement: An Overview", Educational Psychologist, (25 (1), 1990), h. 3-17.

26. B. J. Zimmerman, Self-Regulated Learning and Academic Achievement: An Overview, h. 3-17

27. S.G. Paris \& L. R. Ayres, Becoming Reflective Students and Teachers: With Portfolios and Authentic Assessment, (1994).

28. E. Panadero, \& J. A. Tapia, “How Do Students Self-Regulate? Review of Zimmerman's Cyclical Model of Self-Regulated Learning", Anales de Psicología, (vol. 30, No. 2, 2014), h. 450-462.

29. A. Bandura, Social Foundations of Thought and Action: A Social Cognitive Theory, (New Jersey: Prentice Hall, Inc. Englewood Cliffs, 1986),

30. Ibid.

31. Ibid.

32. B. J. Zimmerman, "A Social Cognitive View of Self-Regulated Academic Learning", Journal of Educational Psychology, (Vol. 81, Issue 3),

33. P. R. Pintrich, "A Conceptual Framework for Assessing Motivation and Self-Regulated Learning in College Students", Educational Psychology Review, (Vol. 16, No. 4, 2004), h. 385407.

34. Ibid.

35. Ibid.

36. Ibid.

37. P. R. Pintrich, D. A. F. Smith, T. Garcia, \& W. J. McKeachie, A Manual for the Use of the Motivated Strategies for Learning Questionnaire (MSLQ), (Ann Arbor: University of Michigan, National Center for Research to Improve Postsecondary Teaching and Learning, 1991).

38. P. R. Pintrich, A Conceptual Framework for Assessing Motivation and Self-Regulated Learning in College Students, (2004), h. 385-407.

39. A. M. Kosnin, "Self-Regulated Learning and Academic Achievement in Malaysian Undergraduates", International Education Journal, 8(1), (2007), h. 221-228.

40. M. Arabzadeh, P. Kadivar, \& A. Dlavar, The Effects of Teaching Self-Regulated Learning Strategy on Students' Academic Delay of Gratification, (2012).

41. J. Tavakolizadeh, \& S. E. Qavam, "Effect of Teaching of Self-Regulated Learning Strategy on Attribution Styles in Students", Electronic Journal of Research in Educational Psychology, 9(3). No. 25. (2011)

42. Carlo Magno, "Self-Regulation and Approaches to Learning in English Composition Writing”, TESOL Journal, (Vol. 1, 2009), h. 1-16.

43. D. Maulia, "Pelatihan Belajar Berdasar Bbegulasi Diri untuk Menurunkan Prokrastinasi Akademik Penulis Skripsi pada Mahasiswa", Tesis, (Fakultas Psikologi UGM, 2011),

44. N. Apranadiyanti, "Hubungan antara Regulasi Diri dengan Motivasi Berprestasi Kelas X SMK Semarang”, Tesis, (Fakultas Psikologi Universitas Diponegoro Semarang, 2010), 


\section{DAFTAR PUSTAKA}

Apranadiyanti, N. Hubungan antara regulasi diri dengan motivasi berprestasi kelas X SMK Semarang. Fakultas Psikologi Universitas Diponegoro Semarang. (2010)

Arabzadeh, M., Kadivar, P., \& Dlavar, A. The effects of teaching self-regulated learning strategy on students' academic delay of gratification. Interdisiplinary Journal Of Contemporary Research Business, Vol. 4, No. 2. (2012)

Ashar, Khusnul. Tahun 2012 jumlah mahasiswa S1 FEB UB yang drop out sebanyak 70 orang. Diakses dari http://feb.ub.ac.id/tahun-2012-jumlah-mahasiswa-s1-febub-yang-di-drop-sebanyak-70-orang.html\#.VBYpi6MZh Ow pada tanggal 12 September 2014.

Balapumi, R., \& Aitken, A. Concepts and Factors Influencing Independent Learning in IS HigherEducation. 23rd Australasian Conference on Information Systems. (2012)

Bandura, A. Social foundations of thought and action: A social cognitive theory. New Jersey: Prentice Hall, Inc. Englewood Cliffs. (1986)

Boekaerts, M., \& Cascallar, E. How far have we moved toward the integration of theory and practice in self-regulation?. Educational Psychological Review, 18: 2006.

Boekaerts, M., \& Niemivirta, M. Self-regulated learning: Finding a balance between learning goals and ego-protective goals. Dalam M. Boekaerts, P. R. Pintrich, dan M Zeidner. Handbook of self-regulation. Sandiego: Academic Press, 2000.

Cohen, M. T. The importance of self-regulation for college student learning. College Student Journal, Vol. 46, No. 4, 2012.

Hoyle. Rick H. Personality and self-regulation: Trait and information-processing perspectives. Journal of Personality, 74:6, 2006.

Ifenthaler, D. Determining the effectiveness of prompts for self-regulated learning in problem-solving scenarios. Educational Technology \& Society, 15 (1), 2012. Kosnin, A. M. Self-regulated learning and academic achievement in Malaysian undergraduates. International Education Journal, 8(1), 2007.

Kramarski, B., \& Michalsky, T. Investigating preservice teachers' professional growth in self-regulated learning environments. Journal of Educational Psychology, Vol 101(1), 2009.

Magno, Carlo, Self-regulation and approaches to learning in english composition writing. TESOL Journal, Vol. 1, 2009.

Maulia, D. Pelatihan belajar berdasar begulasi diri untuk menurunkan prokrastinasi akademik penulis skripsi pada mahasiswa. Tesis. Fakultas Psikologi UGM, 2011.

Miller, R. B., \& Brickman, S. J. A model of future-oriented motivation and selfregulation. Educational Psychology Review, Vol. 16, No. 1, 2004. 
Montalvo, F.T., \& Tores, Maria C.G. Self-regulated learning: Current and future direction. Spain: Department of Education, Univerdad de Navarra, 2004.

Núñez, J. C., Cerezo, R., Bernardo, A., Rosário, P., Valle, A., Fernández, E., \& Suárez, $\mathrm{N}$. Implementation of training programs in self-regulated learning strategies in Moodle format: Results of a experience in higher education. Psicothema. Vol. 23, No. 2, 2011.

Panadero, E., \& Tapia, J. A. How do students self-regulate? Review of Zimmerman's cyclical model of self-regulated learning. Anales de Psicología, vol. 30, no 2 , 2014.

Paris, S. G. \& Ayres, L. R. Becoming reflective students and teachers: With portfolios and authentic assessment. Washington DC: American Psychological Association, 1994.

Pintrich, P. R. A conceptual framework for assessing motivation and self-regulated learning in college students. Educational Psychology Review, Vol. 16, No. 4, 2004.

-----. The role of goal orientation in self-regulated learning. Dalam M. Boekaerts, P. R. Pintrich, \& M. Zeidner (Eds.), Handbook of self-regulation (pp. 451-502). San Diego, CA: Academic, 2000.

Pintrich, P. R., Smith, D. A. F., Garcia, T., \& McKeachie, W. J. A manual for the use of the Motivated Strategies for Learning Questionnaire (MSLQ). Ann Arbor: University of Michigan, National Center for Research to Improve Postsecondary Teaching and Learning, 1991.

Tavakolizadeh, J., \& Qavam, S. E. Effect of teaching of self-regulated learning strategy on attribution styles in students. Electronic Journal of Research in Educational Psychology, 9(3). No. 25, 2011.

Valle, A., Núñez, J. C., Cabanach, R.G., González-Pienda, J. A., Rodríguez, S., Rosário P., ... Muñoz-Cadavid, M. A. Self-regulated profiles and academic achievement. Psicothema. Vol. 20, no 4, 2008.

Winne, P.H. A perspective on state-of-the-art research on self-regulated learning. Instructional Science, 33: 2005.

Zimmerman, B. J. A social cognitive view of self-regulated academic learning. Journal of Educational Psychology, Vol. 81, Issue 3., 1989.

------. Self-regulated learning and academic achievement: An overview. Educational Psychologist, 25 (1), 1990.

------. Attaining self-regulated : A social cognitive perspective. Dalam M. Boekaerts, P. R. Pintrich, dan M Zeidner. Handbook of Self-Regulation. Sandiego: Academic Press, 2000.

. Becoming a self-regulated learner: An overview. Theory Into Practicve, Vol.41, No.2, 2002.

------. Investigating self-regulation and motivation: Historical background, methodological developments, and future prospects. American Educational Research Journal, Vol. 45, No. 1, 2008. 